\title{
GAIFEROS Y SU CABALLO. AVATARES DE UN ROMANCE, DEL QUIJOTE A LA TRADICIÓN ORAL MODERNA
}

Los romances de tema carolingio gozaron de gran popularidad en España durante el Siglo de Oro gracias a su difusión en Cancioneros y pliegos sueltos, difusión que contaba además con la memoria colectiva del pueblo que los transmitía por vía oral ${ }^{1}$. Editores e impresores aprovecharon a la vez que promovieron la afición del público por esos relatos novelescos que se desarrollaban en un ambiente caballeresco.

Las historias de Valdovinos, del marqués de Mantua, de los valientes Durandarte, Lanzarote, Montesinos o Gaiferos, contadas por los romances, eran, como recuerda el inefable don Quijote, "sabida[s] de los niños, no ignorada[s] de los mozos, celebrada[s] y aun creída[s] de los viejos"2 (I, 5).

Son bien conocidas las teorías de Ramón Menéndez Pidal sobre la mediación de cantos de gesta españoles, hoy desaparecidos, entre las chansons de geste francesas y los romances juglarescos de tema carolingio que se popularizaron hasta integrarse al acervo de romances tradicionales españoles. En lo que concierne al romance de Gaiferos libera a Melisendra, señala la canción del sur de Francia, catalana y piamontesa, llamada la Escriveta, como su más probable antecesor ${ }^{3}$. A esta

1 Sobre la difusión del Romancero en los Siglos de Oro es obligada la referencia a los estudios de Giuseppe di Stefano. Véase "La difusión impresa del romancero antiguo", RDTP, 33 (1977), 373-411.

2 Las citas del Quijote, de Miguel de Cervantes, proceden de la edición del Instituto Cervantes, dirigida por Francisco Rico, Galaxia de Gutenberg-Círculo de Lectores, Barcelona, 2004. A fin de hacer menos pesada la anotación, señalo únicamente aquellos capítulos diferentes al 26 de la Segunda parte, en el que se centra este trabajo.

3 Ramón Menéndez Pidal, Romancero hispánico (hispano-portugués, americano y sefardi). Teoría e historia, Espasa Calpe, Madrid, 1953, t. 1, pp. 289-292. Menéndez Pidal consideraba el romance de Gaiferos un romance pseudo-carolingio, pero como han propuesto estudiosos como Rita Lejeune ("Le personage de Gautier del Hum dans la Chanson de Roland", en La technique littéraire des chansons de geste, Université, Liège, 1939, pp. 237-270), Peter Dronke y Ursula Dronke (Barbara et antiquissima carmina, Universidad Autónoma de Barcelona, Barcelona, 1977, pp. 59-60) y SAMUEL 
propuesta de Menéndez Pidal sobre el origen del romance de Gaiferos deben sumarse los importantes estudios de Samuel G. Armistead quien considera al poema épico germano-latino del siglo x, Waltharius, y a sus congéneres germánicos como sus más lejanos antecesores genéticos ${ }^{4}$, una teoría que discute desde su particular punto de vista Víctor Millet en el libro que dedica a ese romance ${ }^{5}$.

En cuanto a la tradición oral moderna del romance, contamos con más de sesenta textos recogidos en España (León, Zamora, Galicia, Andalucía, Cataluña y Baleares), en Portugal (Trás-os-Montes) y en comunidades sefarditas de Oriente (Istib, Larissa, Salónica, Istanbul y Jerusalén), preciosos testigos de los diferentes tipos del romance que debieron circular en tiempos de Cervantes, así como de las diversas "lecturas" que han hecho del tema a través de siglos sus receptores/transmisores ${ }^{6}$.

Indudablemente, el participante más famoso en la cadena de transmisión del romance de Gaiferos libera a Melisendra es Miguel de Cervantes, quien lo recrea genialmente en la Segunda parte del Quijote, en el muy estudiado episodio sobre el retablo de maese Pedro, un capítulo que ha sido considerado por la crítica como una especie de microcosmos de la novela?.

Aunque sea temerario pretender agregar algo nuevo a lo dicho por tanto especialista, quiero detenerme en ese momento de la vida del romance, ya que Cervantes lo aprovecha en su novela, como suele hacerlo con todo material literario, tanto de origen tradicional como

G. Armistead (Folk literature of the Sephardic Jews, t. 5: Judeo-Spanish ballads from oral tradition IV. Carolingian ballads [3]: "Gaiferos", Juan de la Cuesta, Newark, DE, 2005), el héroe germánico Waltharius y Walter del Hum, personaje de La Chanson de Roland, son el mismo, con lo que Gaiferos sería un auténtico caballero carolingio.

4 Armistead, además de considerar el Waltharius como antecedente indirecto del romance, agrega el Waldere anglosajón y el episodio de Valtari en la Thidrekssaga, en nórdico antiguo, como textos igualmente emparentados con Gaiferos. Además del libro arriba citado, véase S.G. Armistead y J. Silverman, "Gaiferos y Waltharius, paralelismos adicionales”, en Homenaje al profesor Antonio Vilanova, eds. A. Sotelo Vázquez y M.C. Carbonell, Universidad Autónoma de Barcelona, Barcelona, 1989, t. 1, pp. 31-43.

5 Víctor Millet, Épica germánica y tradiciones épicas hispánicas: Waltarius y Gaiferos, Gredos, Madrid, 1998.

6 S.G. Armistead edita, analiza y anota exhaustivamente los textos recogidos de la tradición sefardí. Véase el volumen arriba citado de Folk literature of the Sephardic Jews y el libro, igualmente citado, de V. Millet, en el que reproduce los textos conocidos del romance.

7 La centralidad de este capítulo en la novela ha sido propuesta, entre otros, por George Haley, “The narrator in Don Quijote: Maese Pedro's puppet show", MLN, 80 (1965), 145-165; RUTH EL SAFAR, "The function of the fictional narrator in Don Quixote", MLN, 83 (1968), 164-177; Manuel Durán, "El Quijote visto desde el retablo de Maese Pedro", Anthropos, 98/99 (1989), 101-103, y Alberto Castilla, "El retablo de Maese Pedro", Anthropos, 100 (1989), 56-59. 
culto, de tal forma que lo convierte en un engranaje importante de su genial invención, además de que supera a menudo a sus modelos.

Como inspiración de la aventura de don Quijote con motivo de la representación del retablo de maese Pedro, la crítica ha señalado el episodio del Quijote de Avellaneda en el que el falso Quijote ataca a los representantes que ensayan la comedia de Lope de Vega, El testimonio vengado, en una venta cerca de Alcalá ${ }^{8}$.

Es probable que la idea de que don Quijote irrumpiera en la representación con títeres del romance de Gaiferos haya surgido, efectivamente, de la intervención del falso Quijote durante el ensayo de la comedia que aparecía en el texto de Avellaneda, dado el enorme enojo de Cervantes ante el plagio de su criatura y su deseo de demostrar su propia genialidad, lo que lo llevó a utilizar algunas partes de la obra de su imitador como punto de partida de diversos episodios de su legítima Segunda parte de las aventuras de don Quijote.

Imitación o no, no me parece fortuito que Cervantes utilizara precisamente el romance de Gaiferos libera a Melisendra en ese punto de la trayectoria del verdadero don Quijote ${ }^{9}$.

Un detalle importante en cuanto al texto de Avellaneda es que, según se nos informa, la intriga de la comedia de Lope que ensayan los comediantes en la venta tiene como punto de partida la calumnia que le levanta a la reina su hijo, quien, instigado por el demonio y agraviado porque le niegan un "caballo cordobés" que el rey le había concedido, la acusa de infidelidad ${ }^{10}$. Como veremos, un caballo es igualmente central para el romance de Gaiferos que Cervantes aprovecha para crear su propio relato.

Puesto que se trata de una utilización cómica del romance, algunos críticos señalan como posible influencia el Entremés de Melisen$d r a$, que fuera atribuido a Lope de Vega o al mismo Cervantes ${ }^{11}$. Pero hay diversos testimonios de que el tema era parodiado de muchas maneras, como lo hizo Góngora con su romance "Desde Sansueña a París”, Pedro de Moncayo con "El cuerpo preso en Sansueña”, Miguel Sánchez con "Oíd señor don Gaiferos"12, o como se hacía en otros

8 Cap. 27. Las citas de la obra de Avellaneda proceden de la ed. de L. Gómez Canseco: Alonso Fernández de Avellaneda, El ingenioso don Quijote de la Mancha, Editorial Biblioteca Nueva, Madrid, 2000.

9 Coincido con la opinión de Michel Moner de que Cervantes no utiliza materiales por casualidad, sino por voluntad comunicativa y estética, lo que él llama "virtuosidad del creador”. Véase Cervantes conteur, Casa de Velázquez, Madrid, 1989, p. 9.

10 Quijote de Avellaneda, p. 595.

11 Colección de entremeses, loas, bailes, jácaras y mojigangas desde fines del siglo XVI a mediados del XVIII, Bailly-Bailliere, Madrid, 1911, t. 5, pp. 105a-111a (NBAE, 17).

12 Luis de Góngora, Romances, ed. crítica A. Carreira, Quaderns Crema, Barcelona, 1998; Pedro de Moncayo, Flor de romances nuevos (1591); Miguel Sánchez, Flor de romances (1609). 
tipos de piezas representables, tal es el caso de una danza de la fiesta madrileña de Corpus en 160913 .

A pesar de que existían numerosas parodias del romance, y hasta versiones "a lo divino", como la compuesta por Juan López de Úbe$\mathrm{da}^{14}$, no creo que hicieran falta a Cervantes para utilizarlo de manera que entretuviera e hiciera reír a sus lectores, ya que, como sabemos, da este mismo giro a otros romances a lo largo de su novela ${ }^{15}$.

Lo que sí hace Cervantes es utilizar elementos, potenciados por el relato romancístico, para dar al espectáculo de títeres una comicidad propia de esas representaciones, como los coscorrones, que según interpreta el trujamán, quisiera asestar Carlomagno con su cetro al renuente héroe que se entretiene jugando a las tablas en vez de ir a rescatar a su esposa cautiva, una dramatización de la "vehemencia y ahínco" con que el emperador riñe a Gaiferos, que en el romance se dice son "palabras de gran pesar":

Si assí fuéssedes Gayferos, como soys para los dados vuestra esposa tienen moros para las armas tomar y para las tablas jugar, yríades la a buscar ${ }^{16}$,

que a su vez producen "cólera e impaciencia" por parte de Gaiferos que arroja las tablas, los dados o los naipes que tiene en la mano, una acción que en algunas versiones del romance no se lleva a cabo ya que, se nos dice, representaría una afrenta a su contrincante en el juego, Guarinos, Almirante de la mar17.

El chusco detalle del moro que roba un beso a Melisendra provocando el asco de la princesa, podría haber sido inspirado en el desdén de Melisendra por los "muchos reyes moros" que la pretenden en

13 Véase James VArey, Historia de los títeres en España, Revista de Occidente, Madrid, 1957, p. 251.

14 Cancionero general de la doctrina cristiana hecho por Juan López de Úbeda (1579, 1585, 1586), ed. A. Rodríguez Moñino, Sociedad de Bibliófilos Españoles, Madrid, 1962 y 1964.

15 En su importante ensayo, "Quijotey Romances: usos y funciones”, en Historia, reescritura y pervivencia del Romancero. Estudios en memoria de Amalia García Valdecasas, ed. R. Beltrán, Universitat, València, 2000, pp. 25-65, Julio Alonso Asenjo estudia la función cómica del romance de Gaiferos. En su opinión, los romances dan claves para la interpretación del Quijote y constituyen sus elementos estructurales máximos.

16 Para las citas de la tradición antigua utilizo la versión publicada en el Cancionero de Romances (Anvers, 1550), según la ed. de A. Rodríguez Moñino (Castalia, Madrid, 1967). "Romance de don Gayferos que trata de cómo sacó a su esposa que estava en tierra de Moros", pp. 148-156.

17 S.G. Armistead estudia el significado del juego que se interrumpe violentamente en su artículo: "Game of chance: A formulaic theme in the Romancero", LCo, 19 (1990-91), 132-144. 
el relato romancístico. De igual manera, el tan discutido detalle del faldellín de Melisendra que se atora en los hierros del balcón cuando se descuelga para ponerse en las ancas del caballo de Gaiferos, considerado por la crítica una especie de "accidente" de la representación misma ${ }^{18}$, está potenciado por el romance según nos revelan versiones recogidas de la tradición oral moderna de Trás-os Montes: "saltou da varanda abaixo"; de las islas Baleares: "La dama que sent axó, / ja no's pogué deturar; // d’alegría que tenía, / per la finestra’s tirá", o en la tradición sefardí oriental, "Ansí se echó la Miliselda / como quien se echa en la mare"19.

Es evidente que Cervantes conocía bien el romance de Gaiferos libera a Melisendra, independientemente de la "inexactitud" que algunos críticos le echan en cara en los versos que cita, suponiendo que provienen de la tradición impresa del romance que se conserva. Pero no solamente nuestro conocimiento de los textos que circulaban en los Siglos de Oro es sumamente limitado, la tradición oral moderna nos proporciona pistas de tipos de versiones del romance de Gaiferos diferentes a las que se conservan en pliegos y cancioneros de los siglos áureos, sino que, como sucedía con otros receptores/transmisores de romances y en especial cuando se trataba de romances largos, a pesar de su intención de repetir fielmente un texto, lo alteraban, sin por ello afectar las grandes líneas de la tradición. A todo ello hay que sumar además las versiones tradicionales que seguramente escuchó Cervantes de boca de quienes, como él, tenían los romances en la memoria ${ }^{20}$.

Cervantes era un buen conocedor de romances, se sabía de memoria muchos de ellos a juzgar por las citas que incorpora en sus obras, por lo que tiene que haber sido un buen descodificador del significado de esos relatos. Por ello, en mi opinión, debemos ir más allá de la comicidad con que aprovecha el romance de Gaiferos, al sentido global del relato, el que seguramente guió a Cervantes en la elaboración del episodio.

18 Véase, sobre todo, el artículo de John J. Allen, "Melisendra's mishap in Maese Pedro's puppet show", MLN, 88 (1973), 330-335.

19 Véase S.G. Armistead, Judeo-Spanish ballads, p. 29.

20 El romance era tan conocido que SEbastián de Covarrubias lo registra (“Asentado está Gaiferos / en el Palacio Real”) en su Tesoro de la lengua castellana o española (véase la ed. de I. Arellano y R. Zafra, Universidad de Navarra-Iberoamericana-Vervuert, Pamplona-Madrid-Frankfurt/M., 2006 [1611]). Armistead propone que Cervantes seguramente conocía variantes del romance diferentes a la que aparece publicada en los cancioneros y pliegos sueltos del siglo xvi que se conservan. Véase la entrada "Gaiferos", elaborada por S.G. ArmisteAd, en la Gran enciclopedia cervantina, dir. C. Alvar, Castalia, Alcalá de Henares, 2005-2007. 
Con base en la tradición impresa antigua (Di Stefano) y en la tradición oral moderna (Catalán), Giuseppe di Stefano ${ }^{21}$ y Diego Catalán ${ }^{22}$ han propuesto que el romance de Gaiferos libera a Melisendra es un relato de "iniciación" o "prueba" de un héroe. En ambas tradiciones, excepción hecha del tipo de versiones que comienzan directamente con el encuentro entre Gaiferos y Melisendra ${ }^{23}$, el relato se inicia poniendo en evidencia la falta de autoridad moral del protagonista, quien se dedica a jugar a las tablas en vez de tratar de liberar a su esposa, cautiva en tierra de moros. El reclamo que hace el emperador Carlomagno a Gaiferos, al exigirle que cumpla con su deber como esposo y como caballero, es el detonador de las acciones que van a constituir el rito de pasaje que lo probará finalmente como caballero.

Con esa tendencia a la redundancia significativa propia de la literatura tradicional, la inmadurez e irresponsabilidad del caballero es reiterada en el relato por medio de una secuencia que narra la dificultad que tiene Gaiferos para que Roldán, su primo, le proporcione las armas y montura necesarias para lograr el rescate de su esposa. Roldán se niega inicialmente a prestarle su caballo y su espada declarando que Gaiferos carece de la experiencia y carácter que debía tener para utilizarlas, una marca del verdadero caballero que estaba claramente establecida en las leyes de caballería: "Que los caballeros deven ser sabidores de conocer bien los cavallos e las armas que tovieren", como señalaba el Doctrinal de los caballeros ${ }^{24}$.

Esta secuencia no es solamente reiterativa de las carencias que tiene el joven Gaiferos como caballero, sino que tiene especial importancia para el desarrollo del relato, ya que las armas y, de manera especial el caballo que le proporciona Roldán, van a ser los medios ("adyuvantes") esenciales para que pueda cumplir con la hazaña. La tradición oral moderna, con su tendencia a la esencialización del relato, elimina numerosos detalles, pero el caballo mantiene su protagonismo.

21 G. Di Stefano, en su artículo "Gaiferos o los avatares de un héroe", en Estudios románicos dedicados al profesor Andrés Soria Ortega, Universidad, Granada, 1985, pp. 301-311, analiza dos tipos de tradición, la correspondiente a la versión larga ("vulgata") publicada con leves variantes en pliegos sueltos y cancioneros en el siglo XVI, y la que representa una versión más breve publicada en un pliego suelto del siglo xvi de la Biblioteca Nacional de Madrid, que esencializa el mensaje de rito iniciático del romance.

22 "El Romancero de tradición oral en el último cuarto del siglo xx", en $\mathrm{El}$ Romancero hoy. Nuevas fronteras, eds. D. Catalán et al., C.S.M.P, Madrid, 1979, t. 1, pp. 249-253.

23 "Cavallero, si a Francia ides, / por Gayferos preguntad", registrado en el Cancionero musical de la Casa de Medinacelli (mediados del siglo XvI), en el Cancionero sevillano de Nueva York (Hispanic Society) y en la Rosa de amores de Timoneda (1573), entre otros cancioneros y pliegos sueltos.

24 Alonso de Cartagena, Doctrinal de los cavalleros, ed. J.M. Viña Liste, Universidade, Santiago de Compostela, 1995, p. 28. 
Cervantes, como veremos, también considera al caballo esencial para el relato. No solamente el caballo le permite a Gaiferos llegar rápidamente a Sansueña donde se encuentra su esposa: "Jornada de quinze días / en ocho la fue andar" (tradición antigua) o "El caballo no corría / parecía un gavilán // para llegar al palacio / donde Melisendra está", en la tradición moderna, sino que una vez localizada, deben escapar de los moros que la tienen cautiva, para lo cual Gaiferos depende, precisamente, del caballo de cualidades excepcionales que le proporcionó Roldán:

-Las mañas de mi caballo dándole una sopa en vino y apretándole la cincha siete batallas de moros yo te las voy a enseñar:

y una corteza de pan y aflojándole el petral, bien las había saltar ${ }^{25}$.

Después de que logra rescatar a Melisendra, para probarse finalmente como caballero, Gaiferos tiene que probarse como guerrero venciendo a los moros que tenían cautiva a su esposa, una acción en la que nuevamente juega un papel importante el caballo:

Si bien pelea Gayferos tantos mata de los moros de la sangre que dellos salía el cavallo mucho más, que no hay cuento ni par; el campo cubierto se ha...

(trad. antigua),
Tantos moros van tras ellos si el cristiano mata muchos, que el sol hacen nublare, el caballo mata más26

(trad. moderna).

Una vez superada esa prueba, Gaiferos y Melisendra logran salir con bien y nuestro caballero regresa a la corte de Carlomagno en donde es finalmente reconocida su calidad de héroe:

Los doze a don Gayferos tiénenlo por esforzado gran acatamiento le hazen mucho más de allí delante

(trad. antigua).

25 Versión de Chano, León, recitada por Felipe Cerecedo García de 62 años y recogida por Julio CAMARENA el 4 de noviembre de 1985 (publicada en el Romancero general de León. Antología 1899-1989, Seminario Menéndez Pidal-Diputación Provincial de León, Madrid, 1991, t. 1, pp. 81-82). En varias versiones el caballo mismo exige un trato especial.

26 Versión de Guímara, León, recitada por Emeterio Ramón Ramón de 55 años. Recogida por J. Antonio Cid, Bárbara Fernández, Margarita Pazmany y Ana Valenciano el 22 de septiembre de 1979 (ibid., pp. 79-80). 
Cervantes sabe que se trata de un relato de "prueba" de un caballero y sigue de cerca la trama del romance. ¿Por qué traerlo a cuento en ese punto de la trayectoria de don Quijote, si cuando se topa con maese Pedro ya había dejado de ser el Caballero de la Triste Figura que para probarse como caballero andante se embarcaba en aventuras que resultaban en fracasos, y se había convertido en el Caballero de los Leones, después de haberse enfrentado a un león de carne y hueso; una aventura en la que no habían valido encantos "contra su verdadera valentía”? (II, 17).

Al llegar a la venta manchega, don Quijote ya es un caballero andante probado y reconocido por todos los asistentes a las bodas de Camacho como "Cid en las armas y Cicerón en la elocuencia" al haber defendido con su lanza y con su verbo la causa de Basilio ${ }^{27}$.

Lo que sucede es que a pesar de haberse probado como caballero, después de encontrarse en la cueva con sus héroes, Montesinos y Durandarte, en trágica decadencia y con la sin par Dulcinea, convertida en triste y menesterosa labradora, y de no haber podido ayudar a ninguno de ellos -una experiencia que lo enfrentó a una realidad a la vez dolorosa y dudosa dada la posibilidad de que haya sido sólo un sueño-, don Quijote siente la necesidad de ratificar su calidad de héroe defendiendo a otro caballero de Carlomagno.

En la cueva de Montesinos, don Quijote no había podido actuar como caballero andante, además de que se había visto en la necesidad de dudar de su capacidad de distinguir entre realidad y fantasía, aunque no se resigne a que esa realidad, puesta en duda por quienes lo rodean, eche por tierra sus ideales de comportamiento.

Si sus héroes se encuentran encantados, él tiene una mayor responsabilidad como caballero, así que cuando ve en peligro a Gaiferos, anuncia que no va a consentir que en su tiempo y en su presencia "se le haga superchería a un caballero famoso y atrevido enamorado como don Gaiferos", por lo que ataca a los títeres que identifica como enemigos de los cristianos que huyen, sin acordarse de que no era necesario intervenir, dado el final feliz de la historia "verdadera", y de que el caballero cristiano seguramente no necesitaba otra ayuda que la que le podía proporcionar el caballo de Roldán.

Después de su inquietante experiencia en la cueva de Montesinos, don Quijote, por ese “no se qué de escrúpulo" sobre la verdad de lo que vio, había intentado que el mono adivino de maese Pedro le aclarara, de una vez por todas, si lo que había visto era verdad o mentira, pero la "voz del diablo" le responde con el "sí y no" que no resolvía su

27 Véase Beatriz Mariscal, "El Caballero de los Leones y la disputa entre Cupido y el interés", en Actas del Tercer Congreso Internacional de la Asociación de Cervantistas (III-CINDAC), Universitat de les Illes Balears, Palma de Mallorca, 1998, pp. $421-427$. 
duda. Como caballero andante estaba obligado a defender a Gaiferos, si las cosas salieron al revés no fue culpa suya. Lo que vio representado, alega, no era algo que soñó o imaginó, como podía ser el caso de lo visto en la cueva de Montesinos: "Real y verdaderamente os digo, señores que me oís, que a mí me pareció todo lo que aquí ha pasado que pasaba al pie de la letra".

Puesto que se trata de algo real y verdadero, don Quijote exige que lo que pasa en el tinglado se apegue a la verdad: hacer sonar campanas en la ciudad mora de Sansueña no es verosímil, como tampoco corresponde al relato el castigo del moro atrevido o la disquisición sobre la utilización de pruebas en un juicio entre musulmanes.

Si finalmente reconoce que ha causado daño al titiritero, está dispuesto a restituir ese daño, pero lo hace defendiendo la veracidad de las hazañas de Gaiferos, con lo que rechaza pagar los 2 reales y 12 maravedís que le piden por la figura de Melisendra; esa figura, asegura don Quijote, no puede ser Melisendra, puesto que el caballo en el que huían los esposos debía haberlos llevado ya hasta las puertas de París: "porque el caballo en que iban a mí me pareció que antes volaba que corría", dice don Quijote, y aún lo dice la tradición romancística:

Si este fuera el caballo ya cien leguas me tuviera

de mi tío don Roldán, segura de esta ciudad ${ }^{28}$.

A favor de su percepción de la realidad, don Quijote cuenta con un caballo de cualidades excepcionales con el que se salvan Gaiferos y Melisendra.

Su hazaña no es resultado de una falsa percepción de la realidad sin más, además de que pudo haber sido intervenida por los encantadores, hay aspectos de ella que no están siendo tomados en cuenta por quienes lo rodean, lo que seguramente también sucede con el caso de sus héroes y su dama, atrapados en la cueva de Montesinos.

Don Quijote está dispuesto siempre a defender a quienes se encuentren en peligro y a aceptar que algunas de sus acciones puedan tener resultados desastrosos, de ahí que su trayectoria como héroe no sea lineal. El arte de novelar de Cervantes exige esa complejidad.

El romance de Gaiferos libera a Melisendra sirve a Cervantes para crear un gracioso episodio que supera con creces el ideado por su imitador, y a don Quijote, en un momento de crisis, le permite comprobar "el provecho que proporcionan al mundo los caballeros andantes", a la vez que le permite poner a prueba su capacidad para

28 Versión de San Román de los Caballeros, León, recitada por Adelaida Diez Álvarez y recogida (hacia 1970) por Maximino Marcos (Romancero general de León, t. 1, pp. 85-86). 
discernir entre la realidad y la fantasía, un aspecto de su personalidad que otros habían cuestionado, pero que sólo fue materia de autocuestionamiento a partir de la cueva de Montesinos.

Un caballero andante puede tener reveses en su trayectoria, puede inclusive tener alguna falla parcial en su percepción de la realidad, pero no puede dejar de echar mano de su espada cuando se topa con alguien en peligro. Al valiente Caballero de los Leones podían los encantadores quitarle la ventura, pero no "el esfuerzo y el ánimo" (II, 17), con lo que al final de la aventura de Gaiferos puede exclamar: "Viva la andante caballería sobre cuantas cosas hoy viven en la tierra!".

Beatriz Mariscal Hay

El Colegio de México 